\title{
Effect of Native Cassava Starch-Poly (Sodium Acrylate-co-Acrylamide) Hydrogel on the Growth Performance of Maize (Zea may) Seedlings
}

\author{
L. O. Ekebafe, ${ }^{1, *}$, D. E. Ogbeifun ${ }^{2}$, F. E. Okieimen ${ }^{2}$ \\ ${ }^{1}$ Polymer technology department, Auchi Polytechnic, Auchi, Nigeria \\ ${ }^{2}$ Biomaterials research centre, Department of Chemistry, University of Benin, Benin City, Nigeria
}

\begin{abstract}
The physical mixture of native cassava starch and PAN was hydrolyzed by $\mathrm{NaOH}$ solution to yield starch-poly(sodium acrylate-co-acrylamide) superabsorbent hydrogel. The agricultural performance of the hydrogel - soil mixture samples in which maize seedlings have been planted were measured as a function of hydrogel loading and compared with the values obtained in the control in which hydrogel was not added. The results of the soil-hydrogel analysis at a monthly interval showed that there was significant increase in the ability of the soil to retain moisture and also the increase in the growth performance of the maize seedlings compared to the control.
\end{abstract}

Keywords Native Cassava Starch, Hydrogel, Polyacrylonitrile

\section{Introduction}

During the 20th century, the main emphasis of agricultural development all over the world was the increasing productivity per unit area of land used for crop production to feed the ever-increasing population. And this was accomplished through over exploitation of natural resources such as water and plant resources and excessive use of fertilizers and pesticides. Although this practice resulted in considerable increase in crop yields in the short-term, it was not sustainable in the long-run[1]. The productive capacity of the arable land was impaired permanently; the natural water resources were depleted and also polluted with hazardous pesticides and chemical from fertilizers which threatened the survival and well being of all life. Therefore, the emphasis of agriculture development in the present century have shifted to the sustainable maximization of land and water productivity without threatening the environment and the natural resources in view of the climate change effect,[2].

The continued threat to the world's land resources is exacerbated by the need to reduce poverty, climate change and unsustainable farming practices. Climate change is predicted to worsen the incidence of drought and desertification in sub-Saharan African in few years to come[3]. During the last decade, food security was not a global priority, but studies such as the 2020 Vision[4] have shown that food security

* Corresponding author:

lawekebafe@gmail.com (L. O. Ekebafe)

Published online at http://journal.sapub.org/ajps

Copyright (C) 2011 Scientific \& Academic Publishing. All Rights Reserved is one of the main global concerns in this Century. Food security cannot be guaranteed unless the issue of soil erosion, drought, desertification, and soil water management are given the necessary consideration. Superabsorbent polymer hydrogels have a critical role to play here, particularly in the developing countries.

Superabsorbent polymers (SAPs) or hydrogels are loosely cross-linked, three-dimensional networks of flexible polymer chains that carry dissociated, ionic functional groups. They are basically the materials that can absorb fluids of greater than 15 times their own dried weight, either under load or without load, such as water, electrolyte solution, synthetic urine, brines, biological fluids such as urine sweat, and blood[5]

Graft copolymerization of vinyl monomers onto natural polymers is an efficient approach to achieve biopolymer-based superabsorbing hydrogels. Because of their exceptional properties, i.e. biocompatibility, biodegradability, renewability, and non-toxicity.

Free-radical polymerization, however, has several disadvantages. The reproducibility of this method is poor and there is little control over the grafting process, so the molecular weight distribution is polydisperse. In addition, the necessity for gases(e.g. Nitrogen) to prepare an oxygen-free atmosphere and the need for initiators, toxic and/or expensive monomers, and cross-linkers are other disadvantages of free-radical polymerization reactions.

Relatively few or no data are available in the literature on the effect of hydrogel on the physico-chemical properties of soil supporting crop production in developing countries. The present communication describes synthesis of a biopoly- 
mer-based superabsorbent hydrogel based on native cassava Starch and PAN physical mixture. The effect of the hydrogel on the growth performance of maize seedlings in Nigeria.

\section{Materials and Methods}

\subsection{Materials}

Cassava starch was sourced from a local cassava starch processing factory in Benin City, Nigeria. Polyacrylonitrile(PAN) was synthesized through a method mentioned in the literature[6]. Double distilled water was used for the hydrogel preparation and swelling measurements. The soil used was obtained from a farm site at Auchi Polytechnic campus, Auchi, Nigeria and maize grains were purchased from a local market in Auchi, Nigeria.

\subsection{Characterization of the Soil}

The soil samples were characterized as follows: Bulk density was measured by core method, Grossman and Reinsch,[7]. Soil $\mathrm{pH}$ was measured in 1:1 soil-water ratio, Hendershot et al[8]. Soil organic carbon was estimated by combustion at $840^{\circ} \mathrm{C}$, Wang, \& Anderson[9], while total nitrogen was obtained by microkjeldahl method. Cation exchange capacity was measured using ammonium acetate leaching at $\mathrm{pH}$ 7.0, Rhoades[10]. Available phosphorus was determined by Olsen method,[11] and soil heavy metal content was determined using the AAS. The results are as presented in Table 1.

\subsection{Hydrogel Preparation}

A general procedure for alkaline hydrolysis of starch-PAN mixture was conducted as follows. Starch solution was prepared in a 1-1 reactor equipped with mechanical stirrer and gas inlet. In a typical reaction: $1 \mathrm{~g}$ Starch was dissolved in $30.0 \mathrm{ml}$ of distillated degassed water containing $1 \mathrm{wt} . \%$ of acetic acid solution. After complete dissolution of starch, 1.0 weight percent of sodium hydroxide was added to the solution at $90^{\circ} \mathrm{C}$. The mixture was allowed to stir for $120 \mathrm{~min}$. The $1.5 \mathrm{~g}$ polyacrylonitrile was dispersed in the reaction mixture to saponify for $3 \mathrm{~h}$ and $95^{\circ} \mathrm{C}$. During the saponification, $\mathrm{NH}_{3}$ gas was evolved and a color change from red to light yellow. This discoloration was an indication of the reaction completion. The pasty mixture was allowed to cool to room temperature and neutralized to $\mathrm{pH} 8.0$ by addition of $10 \mathrm{wt} \%$ aqueous acetic acid solution. Then, the gelled product was scissored to small pieces and poured in $200 \mathrm{ml}$ ethanol to dewater for $5 \mathrm{~h}$. The hardened particles were filtered and dried in oven $\left(50^{\circ} \mathrm{C}, 10 \mathrm{~h}\right)$. After grinding, the powdered superabsorbent hydrogel was stored away from moisture, heat and light. Hydrogel formation was confirmed on a Nicolet impact 410 FTIR spectrophotometer using a $\mathrm{KBr}$ pellet and the hydrogel surface morphology was examined using scanning electron microscope(SEM).

\subsection{Swelling Measurements Using Tea Bag Method}

The tea bag containing an accurately weighed powdered sample $(0.5 \pm 0.001 \mathrm{~g})$ with average particle sizes of $350 \mu \mathrm{m}$ mesh was immersed entirely in $200 \mathrm{ml}$ distilled water and allowed to soak for $3 \mathrm{~h}$ at room temperature. The tea bag was hung up for $15 \mathrm{~min}$ in order to remove the excess fluid. The Water retention value(WRV) was measured twice using the following equation:

Water retention value $(g / g)=\frac{\left(W_{2}-W_{1}\right)}{W_{1}}$

Where, $\mathrm{W}_{2}$ and $\mathrm{W}_{1}$ are the weights of water swollen hydrogel and dry hydrogel in grams, respectively

\subsection{Soil - Hydrogel Mixing Procedure}

Measured quantities of the hydrogel $(0,3.0,6.0,9.0,12.0 \mathrm{~g})$ were thoroughly mixed with $2 \mathrm{~kg}$ of soil each and designated as $\mathrm{W}_{1}, \mathrm{~W}_{2}$, to $\mathrm{W}_{5}$, placed in five-liter polyethylene containers. Two maize grains were planted in the center of each container. The soil was irrigated with water and the volume of water required to saturate the soil to field capacity was recorded. Subsequent irrigations were applied, the amount of water required to attain field capacity was recorded. Moisture content of the soil was determined by oven-drying aliquots of the soil at $110^{\circ} \mathrm{C}$. Soil samples from the container were collected at one month interval and analyzed for $\mathrm{pH}$, moisture content; cations exchange capacity, soil acidity, Bulk density, water holding capacity, saturation water volume, total organic carbon, and nitrogen using recommended procedures, USDA,(1996)[12].

Biometric data on height, and leaf population of the experimental plants were recorded at bi-weekly intervals. The total amount of water used for irrigation was determined upon completion of the study. Data were analyzed by Analysis of Variance (ANOVA). The results are as presented in Table 2-7.

\section{Results and Discussion}

\subsection{Physico-Chemical Characteristics of the Experimental Soil before Planting}

Textural analysis in Table 1 showed the preponderance of sand fraction( $69.22 \%)$, followed by clay $(16.38 \%)$, then silt $(14.40 \%)$, thus classifying the soil as sandy loam soil[13], this is corroborated by the soil bulk density $\left(1.33 \mathrm{~g} / \mathrm{cm}^{3}\right)$ which is an index of the textural nature of the soil. The slightly alkaline $\mathrm{pH}$ of 8.0 recorded for the soil is within the range of agricultural soils. The $\mathrm{pH}$ of soil influences ion-pair formation, solubility of organic matter, as well as surface charge of $\mathrm{Fe}, \mathrm{Mn}$ and $\mathrm{Al}-$ oxides, organic matter and clay edges[14].

The soil had an average cations exchange capacity(CEC) of $286.02 \mathrm{mg} / \mathrm{kg}$, as showed in Table 1 . The relatively low levels of silt, clay and average level of CEC indicate the high permeability, hence leachability of heavy metals in the soil and suggest that it might be amenable to remediation by use of hydrogel[15,16]. Cations (positively charged ions) useful 
to plant nutrition include $\left.\mathrm{Mg}^{2+(} 67.63 \mathrm{mg} / \mathrm{kg}\right), \mathrm{Ca}^{2+} 2$ $08.51 \mathrm{mg} / \mathrm{kg}), \mathrm{K}^{+}(2.70 \mathrm{mg} / \mathrm{kg}), \mathrm{Na}^{+}(7.18 \mathrm{mg} / \mathrm{kg})$ and $\mathrm{Mn}^{+}$.

Heavy metals analysis of the soil shows that Cadmium and arsenic were not present, as they were not detected by the AAS; however, low levels of Lead $(0.05 \mathrm{mg} / \mathrm{kg})$ and copper $(0.002 \mathrm{mg} / \mathrm{kg})$ were detected, showing the quality level of the soil. The soil organic carbon result, $0.544 \mathrm{~g} / \mathrm{kg}$, in Table 1 , is an indication of the amount of humus/organic matter present in the soil; this is also expressed in the total nitrogen level of the soil, $0.048 \mathrm{~g} / \mathrm{kg}$ (Table 1), which could be as a result of the high rate of organic matter decomposition in the soil. Phosphorus is second to nitrogen in importance in plant nutrient. The available phosphorus result of the soil $(5.889 \mathrm{mg} / \mathrm{kg})$ gives the low level of phosphorus available for uptake by plants.

Table 1. Characterization of the soil before planting begins

\begin{tabular}{cc}
\hline & \\
Analytical characteristics & Results \\
& \\
\hline Particle size distribution $(\%)$ & Clay 16.38 \\
pH & Silt 14.40 \\
Sand 69.22 \\
Bulk Density $\left(\mathrm{g} / \mathrm{cm}^{3}\right)$ & $8.0 \pm 0.01$ \\
Soil organic carbon, $\mathrm{g} / \mathrm{kg}$ & $1.33 \pm 0.02$ \\
Total Nitrogen, $\mathrm{g} / \mathrm{kg}$ & $0.544 \pm 0.05$ \\
Cation exchange capacity,mg/kg & $0.048 \pm 0.002$ \\
Available Phosphorus, $\mathrm{mg} / \mathrm{kg}$ & $286.02 \pm 0.92$ \\
Sodium content, $\mathrm{mg} / \mathrm{kg}$ & $5.889 \pm 0.150$ \\
Potassium content, $\mathrm{mg} / \mathrm{kg}$ & $7.18 \pm 0.07$ \\
Magnesium content, $\mathrm{mg} / \mathrm{kg}$ & $2.70 \pm 0.05$ \\
Calcium content, $\mathrm{mg} / \mathrm{kg}$ & $67.63 \pm 0.25$ \\
Lead $(\mathrm{mg} / \mathrm{Kg})$ & $208.51 \pm 0.55$ \\
Cadmium $(\mathrm{mg} / \mathrm{Kg})$ & $0.05 \pm 0.001$ \\
Arsenic $(\mathrm{mg} / \mathrm{Kg})$ & $\mathrm{ND}$ \\
Copper $(\mathrm{mg} / \mathrm{Kg})$ & $\mathrm{ND}$ \\
Total acidity & $0.002 \pm 0.0005$ \\
\hline
\end{tabular}

ND $=$ Not Detected

\subsection{Mechanism of Hydrogel Formation}

A general reaction mechanism for HSPAN synthesis is shown in Scheme 1. The hydroxyl groups of starch substrate was converted to corresponding alkoxide ions using sodium hydroxide solution. Then, these macroalkoxides initiate crosslinking reaction between some adjacent polyacrylonitrile pendant chains. This reaction leads to intermediate formation of naphthyridine cyclic structures (including imine, $-\mathrm{C}=\mathrm{N}-$, conjugated bonds) with deep red color. The intermediate was then hydrolyzed using residual sodium hydroxide aqueous solution to produce hydrophilic carboxamide and carboxylate groups with a resulting color change from red to light yellow. This sharp color change was used as an indication to halt the alkaline treatment.

Maximum swelling capacity of $682 \mathrm{~g} / \mathrm{g}$ was obtained in water. It has been stated sweeling capacity of hydrogels is influence by the $\mathrm{pH}$, hydrolysis time, temperature and the medium[6]

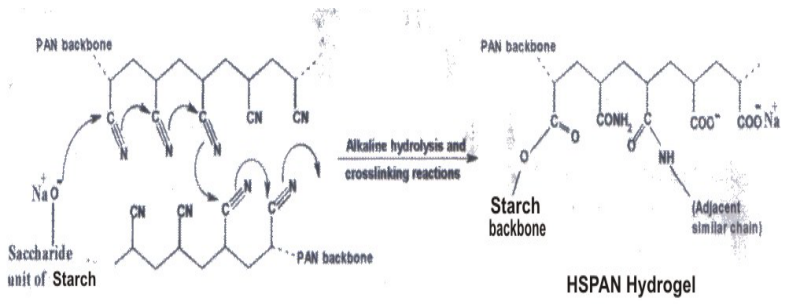

Scheme 1. Proposed mechanism for crosslinking during hydrolyzing nitrile groups of SPAN mixture to produce HSPAN hydrogel

\subsubsection{Infrared Analysis}

Infrared spectroscopy was carried out to confirm the chemical structure of the hydrogel. Figure 1 shows the FTIR spectra of the physical mixture and the resulted hydrogel, St-PAN. The band observed at $2242 \mathrm{~cm}^{-1}$ can be attributed to stretching of $-\mathrm{C} \equiv \mathrm{N}$ group of PAN (Fig. 1a). The hydrogel comprise an starch backbone with side chains that carry carboxamide and carboxylate functional groups that are evidenced by three new peaks at 1407,1556 , and $1675 \mathrm{~cm}^{-1}$ (Fig. 1b). These peaks are attributed to $\mathrm{C}=\mathrm{O}$ stretching in carboxamide functional groups and symmetric and asymmetric stretching modes of carboxylate groups, respectively[6]. As shown in scheme 1. and Fig.1b, after alkaline hydrolysis, most of the nitrile groups are converted to carboxamide and carboxylate groups.

\subsubsection{Hydrogel Morphology}

The surfaces of the hydrogel were observed with SEM. Figure 2 shows the picture of the hydrogel. From the figure it is obvious that the hydrogel has a porous structure. The pores are the regions of water permeation and interactions sites of external stimuli with the hydrophilic groups of the copolymers.

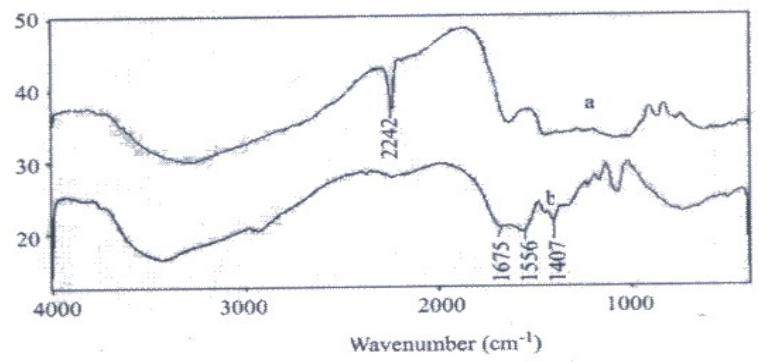

Figure 1. FTIR spectra of (a) starch and PAN mixture, and (b) the cross linked hydrogel

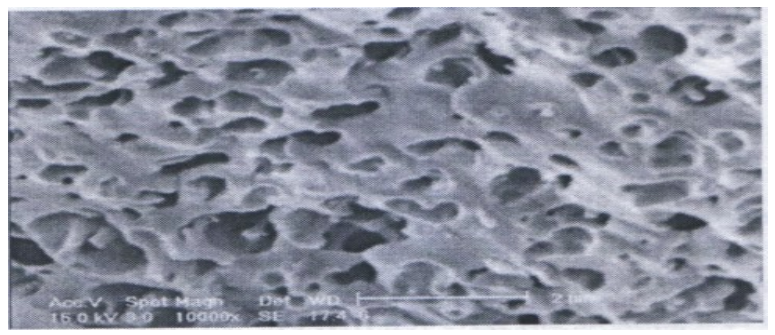

Figure 2. SEM picture of the hydrogel 


\subsection{Effect on the Growth of Maize Seedlings, Water Retention and Physicochemical Properties of the Soil by Starch-based Hydrogel}

Table 2 shows the amount of water uptake by each container beginning from the first two weeks of the study and it shows that the amount of water by kg soil required decreases as the weeks proceeded because of the ability of the hydrogel to store up water for the plant use. The control $\left(\mathrm{W}_{1}\right)$ shows that the amount of water required remains the same because there was no hydrogel to store water. The reduction in water demand of the soil as a result of the addition of the hydrogel shows the cost-effectiveness of the hydrogel in irrigation farming application in Sub-Saharan Africa.

Table 2. Water used by Zea may in polymer amended soil(ml) from the first two weeks of the study

\begin{tabular}{cccc}
\hline $\begin{array}{c}\text { Soil/poly. } \\
\text { Conc/kg. }\end{array}$ & $\begin{array}{c}\text { Water } \\
\text { 2 weeks }\end{array}$ & $\begin{array}{c}\text { Applied to } \\
\text { 4 weeks }\end{array}$ & $\begin{array}{c}\text { Soil(ml) } \\
\text { 6 weeks }\end{array}$ \\
\hline W1 & 325 & 330 & 310 \\
W2 & 400 & 200 & 080 \\
W3 & 475 & 275 & 100 \\
W4 & 550 & 375 & 150 \\
W5 & 750 & 400 & 180
\end{tabular}

Table 3 show the growth of the maize seedlings in terms of height and leaf number of the plant. The table reveals consistent increase in growth and leaf number, which is expected based on the availability of soil nutrients and water. The results show that there are significant effects of irrigation regime on the height and leaf number. The height and leaf number increases from $\mathrm{W}_{1}$ to $\mathrm{W}_{5}$ due to the ability of the soil to make water available to the plant. The control did not show comparable increase in the height and leaf number of the plant.

Table 4 shows that as a result of the application of the hydrogel bulk density increases from $\mathrm{W}_{1}$ to $\mathrm{W}_{5}$, showing expansion of the hydrogel particles upon water absorption increasing aeration and improving drainage, providing faster growth and minimizes the danger of root rot. However, $\mathrm{W}_{1}$ in which the hydrogel was not added shows a decrease from the initial value, because of the nature of the soil, nutrient uptake and leaching.
Saturation water volume (SWV) is the volume of water required by the soil at field capacity. Table 4 shows that the SWV increases from W1 to W5, this is expected because when water is added an electrical repulsion takes place between the hydrogel particles causing Water to be drawn in,resulting in a rapid swelling of each particle and a rapidabsorption of water[17]. However, Table 6, shows that subsequent addition decreases from the initial amount of water absorb because of the ability of the hydrogel to store water for future plant use, thus the subsequent weeks water, the soil takes from $\mathrm{W}_{1}$ to $\mathrm{W}_{5}$ is lesser than the initial requirement.

Tables 2, 4, and 6 shows that moisture content after irrigation increases from $\mathrm{W}_{1}$ to $\mathrm{W}_{5}$ due to the application of the hydrogel to the soil, indicating more water available to the plant and hence increases growth of the plant. Gehring and Lewis[17] reported that moisture stress of plants decreased by incorporation of a hydrogel into the medium. Wallace and Wallace[18] stated that generally the most favourable results for seed emergence and water infiltration came from hydrogel application.

Tables 4 , and 6 show the variation of the $\mathrm{pH}$ of the soil for the period of the experiment, it also shows that there is a near neutral reaction in the soil, an indication of a balance ions availability and activity in the soil. The absorption capacity of hydrogels is affected by acidity and alkalinity $(\mathrm{pH})$, conductivity, and other variables that inhibit expansion of the gel particles[19]. The $\mathrm{pH}$ of the absorbed fluid did not present a problem to the plant since the $\mathrm{pH}$ in the growing environment is normally within the ideal range for optimum absorption. The $\mathrm{pH}$ values varied between the allowable $\mathrm{pH}$ of soils. However, the optimum $\mathrm{pH}$ range for maize growth is in the range of 6.5 to 8.0 ; an indication of the plant adaptation ability to the nature of the soil used for the experiment.

Sandy soils which are coarse-textured, are light soils and are easier to till, they drain better, and are warm. Crop production on sandy soil requires frequent irrigation to make up for its poor water retention capacity. Thus the idea of applying hydrogel therefore is to increase the water retention capacity of the soil as to reduce the frequency of irrigation and its cost implication. A careful study of Tables 2, 4 and 6 reveal that the water retention capacity of the soil increases on application of the starch hydrogel, showing a higher cost effective system for crop production.

Table 3. Biometric observations of the maize plants showing the height and leaf number

\begin{tabular}{|c|c|c|c|c|c|c|c|c|c|c|c|c|c|c|}
\hline $\begin{array}{c}\text { Con- } \\
\text { trol } \\
\text { (W1) } \\
\text { BI- } \\
\text { WEEK }\end{array}$ & $\begin{array}{c}\mathrm{Ht} \\
(\mathrm{dm})\end{array}$ & LN & W2 & $\begin{array}{l}\mathrm{Ht} \\
(\mathrm{dm})\end{array}$ & $\begin{array}{l}\mathrm{L} \\
\mathrm{N}\end{array}$ & W3 & $\begin{array}{c}\mathrm{Ht} \\
(\mathrm{dm})\end{array}$ & LN & W4 & $\begin{array}{l}\mathrm{Ht} \\
(\mathrm{dm})\end{array}$ & LN & W5 & $\begin{array}{l}\mathrm{Ht} \\
(\mathrm{dm})\end{array}$ & LN \\
\hline 2 & 8.5 & 2 & & 10.1 & 2 & & 11.0 & 2 & & 11.0 & 3 & & 12.5 & 4 \\
\hline 4 & 9.5 & 3 & & 10.5 & 4 & & 11.5 & 4 & & 12.0 & 6 & & 12.5 & 6 \\
\hline 6 & 10.1 & 4 & & 11.1 & 6 & & 11.8 & 6 & & 12.5 & 8 & & 13.0 & 8 \\
\hline 8 & 10.5 & 4 & & 11.8 & 8 & & 12.5 & 8 & & 13.0 & 8 & & 14.5 & 10 \\
\hline
\end{tabular}


Table 4. Effect of hydrogel on physical properties of the soil at the end of the $1^{\text {st }}$ month of the study

\begin{tabular}{cccccc}
\hline $\begin{array}{c}\text { Soil/Polymer } \\
\text { conc.( wt. poly/ 2kg } \\
\text { soil) }\end{array}$ & $\begin{array}{c}\text { Bulk den- } \\
\text { sity }\left(\mathrm{g} / \mathrm{cm}^{3}\right)\end{array}$ & $\begin{array}{c}\text { Saturation water } \\
\text { volume (ml/kg) }\end{array}$ & $\begin{array}{c}\text { Soil moisture } \\
\text { after irrigation } \\
(\%)\end{array}$ & $\mathrm{pH}$ & WRC (ml/kg) \\
\hline $\mathrm{W}_{1}(0)$ & 1.24 & 125 & 21.78 & 7.8 & 0 \\
$\mathrm{~W}_{2}(1.5)$ & 1.42 & 140 & 25.56 & 7.6 & 15 \\
$\mathrm{~W}_{3}(3.0)$ & 1.42 & 152.5 & 32.10 & 7.5 & 27.5 \\
$\mathrm{~W}_{4}(4.5)$ & 1.62 & 182.5 & 32.34 & 7.6 & 57.5 \\
$\mathrm{~W}_{5}(6.0)$ & 1.61 & 205.5 & 35.62 & 7.9 & 82.5 \\
\hline
\end{tabular}

Table 5. Effect of hydrogel on Chemical properties of the soil at the end of the $1^{\text {st }}$ month of the study

\begin{tabular}{ccccc}
\hline $\begin{array}{c}\text { Soil/Polymer conc.( wt. } \\
\text { poly/ 2kg soil) }\end{array}$ & CEC $(\mathrm{mg} / \mathrm{kg})$ & $\mathrm{N}(\mathrm{g} / \mathrm{kg})$ & $\mathrm{C}(\mathrm{g} / \mathrm{kg})$ & Total Acidity \\
\hline $\mathrm{W}_{1}(0)$ & 273.72 & 0.07 & 0.544 & 0.22 \\
$\mathrm{~W}_{2}(1.5)$ & 328.52 & 0.058 & 0.615 & 0.34 \\
$\mathrm{~W}_{3}(3.0)$ & 359.57 & 0.056 & 0.643 & 0.26 \\
$\mathrm{~W}_{4}(4.5)$ & 384.45 & 0.056 & 0.687 & 0.41 \\
$\mathrm{~W}_{5}(6.0)$ & 446.98 & 0.054 & 0.721 & 0.52 \\
\hline
\end{tabular}

Table 6. Effect of hydrogel on physical properties of the soil at the end of the study (6 weeks)

\begin{tabular}{cccccc}
\hline $\begin{array}{c}\text { Soil/Polymer } \\
\text { conc. }(2 \mathrm{~kg} \\
\text { soil/wt\% poly) }\end{array}$ & Bulk density $\left(\mathrm{g} / \mathrm{cm}^{3}\right)$ & $\begin{array}{c}\text { Saturation water vol- } \\
\text { ume }(\mathrm{ml} / \mathrm{kg})\end{array}$ & $\begin{array}{c}\text { Soil moisture after } \\
\text { irrigation }(\%)\end{array}$ & $\mathrm{pH}$ & WRC(ml $/ \mathrm{kg})$ \\
\hline $\mathrm{W}_{1}(0)$ & 1.20 & 75 & 19.48 & 7.7 & 0 \\
$\mathrm{~W}_{2}(1.5)$ & 1.41 & 40 & 22.34 & 7.2 & 26.5 \\
$\mathrm{~W}_{3}(3.0)$ & 1.40 & 50 & 28.29 & 7.4 & 33 \\
$\mathrm{~W}_{4}(4.5)$ & 1.61 & 75 & 31.36 & 7.5 & 50 \\
$\mathrm{~W}_{5}(6.0)$ & 1.64 & 90 & 32.51 & 7.8 & 60 \\
\hline
\end{tabular}

Table 7. Effect of hydrogel on chemical properties of the soil at the end of the study (6 weeks)

\begin{tabular}{ccccc}
\hline $\begin{array}{c}\text { Soil/Polymer conc. }(2 \mathrm{~kg} \\
\text { soil/wt\% poly) }\end{array}$ & $\mathrm{CEC}(\mathrm{mg} / \mathrm{kg})$ & $\mathrm{N}(\mathrm{g} / \mathrm{kg})$ & $\mathrm{C}(\mathrm{g} / \mathrm{kg})$ & Total Acidity \\
\hline $\mathrm{W}_{1}(0)$ & 218.25 & 0.060 & 0.614 & 0.15 \\
$\mathrm{~W}_{2}(1.5)$ & 277.97 & 0.057 & 0.472 & 0.31 \\
$\mathrm{~W}_{3}(3.0)$ & 324.75 & 0.046 & 0.632 & 0.38 \\
$\mathrm{~W}_{4}(4.5)$ & 363.53 & 0.067 & 0.738 & 0.35 \\
$\mathrm{~W}_{5}(6.0)$ & 403.17 & 0.071 & 0.832 & 0.46 \\
\hline
\end{tabular}

However, the increase in WRC from $\mathrm{W}_{1}$ to $\mathrm{W}_{5}$ in each table is an indication of the amount of hydrogel applied which increases from $\mathrm{W}_{1}$ to $\mathrm{W}_{5}$, meaning more hydrogel particles available for absorption due to expansion by electrical repulsion of the particles. Also, the change in WHC from week 2 to week 6 ending is due to the initial level of water uptake to field capacity of the soil. The capacity of hydrophilic polymers to provide water to plants depends on the proportion of water held by the polymer that is easily available to plants, the pressure the soil exerts on the polymers, the presence of soluble salts and the ability of the hydrogel to make use of gravitational water, water which is usually not available to plants, as well as capillary water[20].

CEC increases from $\mathrm{W}_{1}$ to $\mathrm{W}_{5}$ in Tables 5 , and 7 , as a result of the soil ability to reduce leaching of cations from the topsoil due to the application of the hydrogel. The use of the hydrogel to enhance water retention capacity also increases the nutrient holding capacity of the medium[38]. The increase can also be interpreted in terms of the counter ions exchange capacity of the hydrogel which increases the soil's; $\mathrm{Ca}^{2+}, \mathrm{Mg}^{2+}, \mathrm{K}^{+}$and $\mathrm{Na}^{+}$ions which constitute the CEC. The increase also is a reflection of the ability of the applied hydrogel to create microcosms that are rich in water and nutrients (counter ions).

The conditions of these microenvironments are favourable to roots and microorganisms. However Tables 5, and 9, show decrease in the variation of the CEC from week 2 to week 6 ending, due to plant uptake of the limiting soil nutrients being a pot experiment. Total soil acidity is the sum total effect of available anions in the soil. Tables 5, and 7, show that there is no significant variation in the total soil acidity probably due to the slow enzymatic action of soil microorganisms, which act to decompose soil organic matter to produce $\mathrm{CO}_{2^{-}}, \mathrm{NH}_{4}{ }^{+}, \mathrm{NO}_{3}^{-}, \mathrm{SO}_{4}{ }^{2-}, \mathrm{H}_{2} \mathrm{PO}_{4}^{-}$and $\mathrm{H}_{2} \mathrm{O}$.

\section{Conclusions}

In the present study, we prepared a superabsorbent hydrogel, native cassava starch-Poly[sodium acrylate-co-acrylamide], by alkaline hydrolysis of starch/PAN physical mixture. The reaction of starch alkoxide anions with 
nitrile groups of polyacrylonitrile, forms crosslinking points and results in a three-dimensional network. Because a polymerization reaction is not involved, so there is no need for initiator, toxic and/or expensive monomer and crosslinker. Therefore, problems such as polymerization control, conversion loss, and residual monomer are eliminated. Indeed, since no toxics material is used for the synthesis, this practical approach may be referred to as a relatively "green process". In addition, this one-step preparative method was conducted under normal atmospheric conditions in a short period of time. The dark red-yellow color change provides a visual indication for recognizing the reaction completion.

The results show that hydrogel prepared from native cassava starch--polyacrylonitrile) physical mixture influenced the physico-chemical properties of soil supporting the growth of maize seedlings significantly, compared to the control.

The results indicate that there is an improvement in the ability of the soil to hold water by reason of the introduction of the hydrogel, thus, this could become cost effective in irrigation of farmlands in Africa. These results are of interest for the development of hydrogel-based technologies for solving the problem of agriculture and water conservation management in sub-Saharan Africa.

\section{REFERENCES}

[1] F. Yazdani, Allahdadi I, Abas Akbari G.2007: Impact of superabsorbent polymer on Yield and Growth Analysis of Soybean (Glycine max L.) under drought stress condition, Pakistan J. Bio. Sci. 10(23): 4190-4196

[2] N.R. Bhat, Suleiman MK, Abdal M, 2009: Select ion of crops for sustainable utilization of Land and Water resources in Kuwait, world J. Agric. Sci.5(2): 201-206

[3] F.C Okorie,: Studies on Drought in the Sub-Saharan Region of Nigeria using Satelite Remote Sensing and Precipitation Data; Department of Geography, of Lagos, Nigeria, 2003

[4] FAO : World Food Security: a Reappraisal of the Concepts and Approaches. Director Generals Report, Rome, 1996

[5] Zohuriaan-Mehr MJ, Kourosh Kabiri, 2008: Superabsorbent Polymer Materials:A Review. Iranian Polymer J.17(6):451-4 77

[6] Sadeghi M, Hosseinzadeh H, 2008: Synthesis and swelling behavior of starch-poly(sodium acrylate-co-acrylamide) superabsorbent hydrogel. Tuk. J. Chem. 32:375-388
[7] R.B Grossman, Ranches. TG, 2002: Bulk Density and linear extensibility in: Dane J.H. Topp. G.C.(eds) Methods of soil analysis, part 4 physical methods. Soil Sci. Am. Book series No. 5 ASA and SSSA. Madison WT; 201-228

[8] W.H Hendershot, H. Lalande, M. Duqyette, 1993: Soil reaction and exchangeable acidity in; carte M.R. (ED) Soil sampling and methods of analysis. Can. Soc. Soil sci. Lweis publisher London, 141-145

[9] D. Wang, D.W. Anderson, 1998: Direct measurement of organic carbon content in soils by leco CR-12 carbon analyzer. Commun. Soil sci. plant Anal.,29:15-21

[10] J.D. Rhoades, 1982: Cation Exchange Capacity in; page A.I. Miller R.H. Keeney D.R. (eds) Methods of soil analysis part 2 American Soc. Agro. Madison W.I.149-158

[11] O. Emteryd,:Chemical and physical analysis of inorganic nutrients in plants soil water and air stencil no. Uppsala Swedish University of Agricultural Sciences, 1989

[12] USDA, Official Methods of Soil Analysis, 1996 edition, Washington D.C., USA, 1996

[13] Soil Survey Staff: Keys to Soil Taxonomy (8th. Ed.), USDA-NRCS, Center Technology Evaluation Report TE- 98-01, 1998:37

[14] S. Tokalioglu, Kartal, S. Gültekin, A: Investigation of heavy-metal uptake by vegetables growing in contaminated soils using the modified BCR sequential extraction, 2006

[15] S. Ehsan, Prasher, SO. Marshall, W D, 2006: A washing procedure to mobilize mixed contaminants from soil: II. Heavy metals. J. Environ. Qual., 35(6): 2084-2091

[16] Pritchard, James F. and Quinn, James J: Super soil moisturizer challenges others in Growing industry; Ornamentals south magazine, 1981

[17] J.M. Gehring, A.J. Lewis, III, 1980: Effects of hydrogel on wetting and moisture stress of bedding plants. J. Amer. Soc. Hort. Sci. 10594: 511-513

[18] A. Wallace, and G.A. Wallace, 1990 : Interactions encountered when applying nitrogen and phosphorus fertilizer and a water-soluble polyacrylamide to soil. J. Plant Nutr,13:343-347

[19] J.Pitchard James and Quinn James J,: Terra-Sorb, A Water management Tool for World crop production. Industrial services internation, inc; 1983

[20] B.C. Bearee R.W. McCollum, 1977: A comparison of peat-lite and non composted hard-wood bark mixes for use in pot and bedding plant production and the effects of a new hydrogel soil amendment on their performance. Flor. Rev. 161(4169):21-23,66 